\title{
Platelet-rich plasma in the treatment of Class II furcation defects: a histometrical study in dogs
}

\author{
Fabrícia Ferreira SUAID1, Marcelo Diniz CARVALHO², Gláucia Maria Bovi AMBROSANO ${ }^{3}$, Francisco Humberto \\ NOCITI JUNIOR ${ }^{4}$, Marcio Zaffalon CASATI ${ }^{5}$, Enilson Antônio SALLUM ${ }^{4}$

\begin{abstract}
1- DDS, MS, Department of Prosthodontics and Periodontics, Division of Periodontics, Piracicaba Dental School, State University of Campinas, Piracicaba, SP, Brazil.

2- DDS, MS, Department of Prosthodontics and Periodontics, Division of Periodontics, Manaus Dental School, State University of Amazonas, Manaus, AM, Brazil. 3- DDS, MS, PhD, Professor, Department of Community Dentistry, Division of Biostatistics, Piracicaba Dental School, State University of Campinas, Piracicaba, $\mathrm{SP}$, Brazil.

4- DDS, MS, PhD, Professor, Department of Prosthodontics and Periodontics, Division of Periodontics, Piracicaba Dental School, State University of Campinas, Piracicaba, SP, Brazil.

5-DDS, MS, PhD, Assistant Professor, Department of Prosthodontics and Periodontics, Division of Periodontics, Piracicaba Dental School, State University of Campinas, Piracicaba, SP, Brazil.
\end{abstract}

Corresponding address: Enilson Antonio Sallum - Faculdade de Odontologia de Piracicaba - UNICAMP - Departamento de Prótese e Periodontia - Av. Limeira, 901 - Areião - Piracicaba - São Paulo - Brasil - 13414-903 - e-mail: easallum@fop.unicamp.br

Received: December 03, 2009 - Modification: May 10, 2010 - Accepted: May 30, 2010

\section{ABSTRACT}

\begin{abstract}
bjective: This study was designed to evaluate the potential adjunctive benefits of platelet-rich plasma (PRP) when used with guided-tissue regeneration (GTR) and bioactive glass (BG) in the treatment of Class II furcation lesions. Material and Methods: Bilateral Class II furcation lesions were surgically created and allowed to become chronic in the mandibular third premolars of 9 dogs. The defects were randomly assigned to: A) GTR+BG and B) GTR+BG+PRP. Similar defects were created in the maxillary third premolars and received the same treatments after 45 days. Dogs were sacrificed 90 days after the first treatment. The histometric parameters evaluated were: connective tissue adaptation, new cementum, new bone, mineralized bone area, non-mineralized bone area, and residual BG particle area. Results: Data analysis showed a superior length of new cementum and a greater mineralized bone area for group $B$ in both periods $(p<0.05)$. The non-mineralized bone area was greater in the control group $(p<0.05)$ in both periods. Conclusion: Within the limits of this study, it can be concluded that the use of PRP in the treatment of Class II furcation defects may enhance the amount of new cementum and provide a more mineralized bone in a shorter period of time.
\end{abstract}

Key words: Periodontal diseases. Platelet-rich plasma (PRP). Regeneration. Furcation defects. Dogs.

\section{INTRODUCTION}

It is recognized that teeth with furcation involvement may undergo a more extensive and rapid clinical probing attachment loss and are lost with greater frequency than single-rooted teeth ${ }^{18}$. Although regeneration of periodontal tissue is the ultimate goal of periodontal therapy, regeneration is not a predictable healing outcome after conventional treatment.

With the advent of regenerative techniques, a new concept of periodontal treatment based on the principle of cellular selection and guided tissue regeneration ${ }^{5}$, permits the treatment of teeth with furcation lesions by conservative surgical methods. Various studies reported gains in horizontal and vertical clinical attachment, with complete closure of the furcation in up to $67 \%$ of the cases using different types of mechanical barriers ${ }^{20,24}$. Despite positive results based on reports of substantial attachment gain and bone fill of furcations, guided-tissue regeneration (GTR) is technique sensitive and could be associated with increased postoperative problems. A major drawback to expanded polytetrafluoroethylene (ePTFE) and other non-resorbable membranes is the need for 
their removal after 4 to 6 weeks, often with a surgical procedure that adds to patient morbidity and may disturb the healing tissue ${ }^{30}$.

Bone replacement grafts have achieved similar results to GTR, demonstrating a $55 \%$ overall improvement, with either complete or partial furcation fill compared to $52 \%$ for GTR2 ${ }^{2}$. The use of bioactive glass (BG) when compared to an ePTFE barrier may produce similar clinical results ${ }^{30}$. When used in a variety of periodontal and oral surgical applications, BG has shown positive clinical and histological outcomes ${ }^{6,16,27}$.

In the past decade, several cytokines, or growth factors, have received attention because they can regulate migration, attachment, proliferation and/ or differentiation of periodontal ligament cells into hard tissue cells and have been shown to enhance regeneration with in vivo experiments ${ }^{4,23}$. A convenient technique to obtain transforming growth factor $\beta$ (TGF $\beta$ ) and platelet-derived growth factor (PDGF) is by preparing autologous plateletrich plasma (PRP) ${ }^{14}$. PDGF has shown to exert a favorable effect on periodontal regeneration as measured by gain in clinical attachment and defect fill in humans ${ }^{8}$.

Considering that the most favorable outcome of periodontal regenerative procedures in furcations lesions has been achieved with a combination of graft material and GTR ${ }^{14,15}$, the goal of the present study was to investigate, histologically and histometrically, the potential adjunctive benefits of PRP when used with GTR and BG in the treatment of Class II furcation lesions.

\section{MATERIAL AND METHODS}

Nine adult female mongrel dogs were included in the experiment (mean weight $=15 \mathrm{~kg}$ ). The study protocol has been approved by the Institutional Committee of Animals Research. The surgical procedures were performed under general anesthesia with intravenous injection of a $3 \%$ sodium pentobarbital solution $(0.5 \mathrm{~mL} / \mathrm{kg})$. The maxillary and mandibular second and fourth premolars had been bilaterally extracted previously and the extraction sites had been allowed to heal for 2 months. Bilateral Class II furcation lesions were surgically created at the buccal aspect of mandibular third premolars. In order to create the defects a buccal mucoperiosteal flap was raised to expose the alveolar buccal bone. Osteotomy was done in the furcation area with high-speed diamond burs with constant irrigation and with Nos. 1 and 2 Oschenbein chisels. The furcations lesions were standardized with a millimeter probe and measured $5.0 \mathrm{~mm}$ in the apico-occlusal direction and $2.0 \mathrm{~mm}$ in the buccolingual direction (Figure 1), following a technique previously described ${ }^{22}$.
The defects were filled with gutta-percha to induce an inflammatory response due to plaque accumulation for a period of one month (Figure 2 ). After this period, scaling and root planing was performed and a regimen of daily brushing plus topical application of $0.1 \%$ chlorhexidine gluconate was instituted for 7 days prior to the surgical procedures.

In the same day of the treatment of the mandibular defects, similar defects were created at the buccal aspect of maxillary third premolars and were exposed to plaque accumulation for 1 month. Forty-five days after this surgical intervention, the maxillary defects were assigned to receive the same treatments.

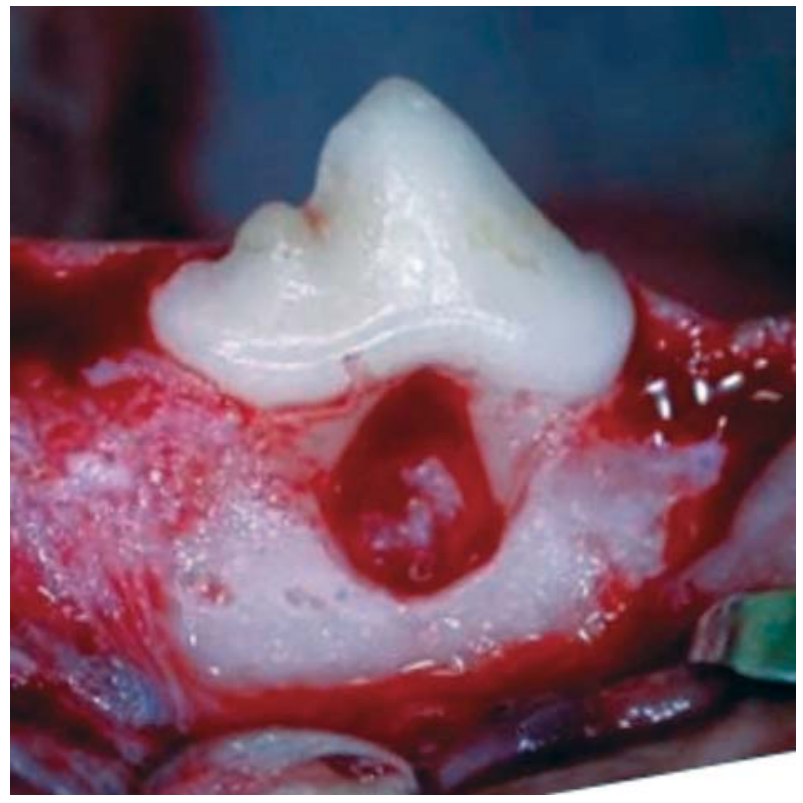

Figure 1- Clinical aspect of Class II furcation defect (5x $2 \mathrm{~mm}$ )

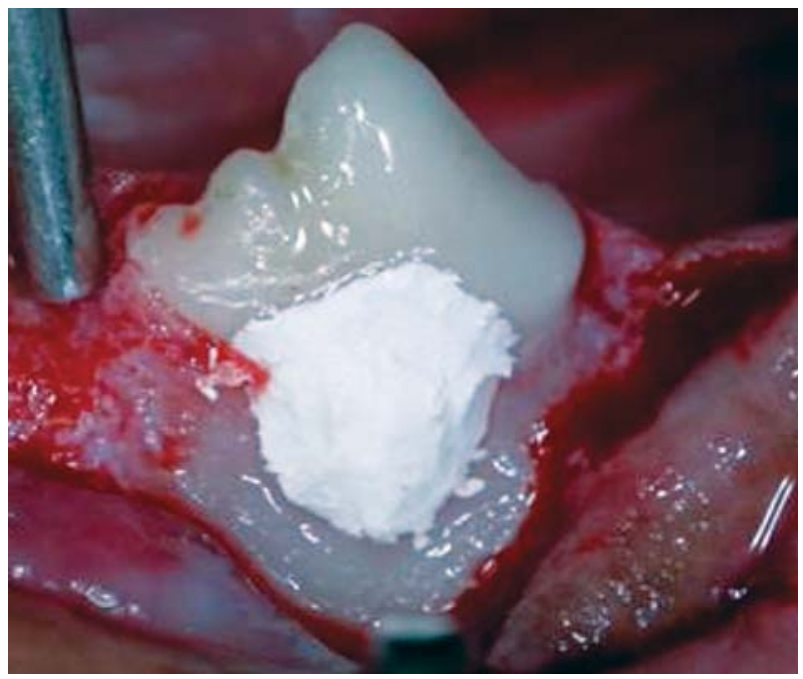

Figure 2- Clinical aspect of Class II furcation defect filled with gutta-percha 


\section{PRP Preparation}

Blood was obtained several min before the administration of anesthesia. Three tubes $(5 \mathrm{~mL})$, containing $0.5 \mathrm{~mL}$ of $3.2 \%$ sodium citrate solution as an anticoagulant, were drawn from each dog. The tubes were centrifuged at 1,200 rpm for 10 min at room temperature. The blood was thus separated into 3 basic parts: red blood cells (at the bottom of the tube), platelet enriched plasma (a discrete grey line in the middle of the tube) and platelet poor plasma (at the top of the tube). The portion corresponding to the platelet poor plasma was discarded from each tube and the remaining content was centrifuged again at 1,200 rpm for 15 min. Four hundred microliter of the middle portion, corresponding to the platelet enriched plasma, were pipetted from each tube. In order to obtain the gel, $30 \mu \mathrm{L}$ of $10 \%$ calcium chloride was added to PRP and heated in a water bath at $37^{\circ} \mathrm{C}$. The gel was achieved after a period of 10 to $15 \mathrm{~min}^{26}$.

\section{Defect treatment}

Mucoperiosteal flaps were carefully reflected on the buccal aspect of the experimental sites, the granulation tissue was removed by curettage, and the exposed root surface was instrumented. On the root surface, the base of the defect was marked with curettes to establish a landmark for the histomorphometric analysis. Each contralateral defect in each animal was randomly assigned to one of the following treatments:

GTR+BG (Perioglas, US Biomaterials, Alachua, FL, USA) - Control group: BG particles were applied filling the defect and absorbable membrane (Resolut $\mathrm{XT}^{\circledR}$ Gore-tex, Gore Associates, Flagstaff, AZ, USA) was adapted to the defect;

GTR+BG+PRP - Test group: BG was incorporated to the PRP (1:1) and this assemblage was immediately taken to a water bath at $37^{\circ} \mathrm{C}$ what enabled the formation of a mixture of the gel and the BG graft. This mixture was applied filling the defect and an absorbable membrane (Resolut $X \mathrm{XT}^{\circledR}$ Gore-tex, Gore Associates) was adapted to the defect.

Primary, tension-free wound closure was accomplished following defect treatment, with the gingival flaps positioned and sutured with interrupted sutures (Vicryl, Ethicon INC, São José dos Campos, SP, Brazil) in order to cover the membranes. Immediately after the surgeries, an intramuscular injection of penicillin $(1.5 \mathrm{~mL}-$ 150,000 IU) was given to the animal.

Forty five days after the mandibular treatment, the maxillary defects ( 2 defects/ animal) were randomly assigned to receive the same treatments (Group A and Group B).

Postoperative plaque control was performed by irrigation with a solution of $1 \%$ chlorhexidine gluconate (every other day). Dogs were sacrificed 90 days after the first treatment, under general anesthesia, with a perfusion of $10 \%$ neutral formalin solution. The jaws were dissected and the blocks containing the experimental specimens were obtained. They were decalcified in a solution of equal parts of $50 \%$ formic acid and $20 \%$ sodium citrate for 5 months. The decalcified specimens were washed in running water, dehydrated and embedded in paraffin. Mesiodistal $7-\mu \mathrm{m}$-thick sections were obtained from the tissue blocks longitudinally, in a buccolingual direction, in a way to obtain a panoramic view of the furcation area. The sections were stained with hematoxylin and eosin.

For histometric and descriptive histological analyses, 5 sections per site representing the middle portion of the defect (30 $\mu \mathrm{m}$ apart) were used to obtain the mean for each parameter in each dog, measured with an image analysis system (Image Pro Plus Version 3.0, Media Cybernetics, Silver Spring, MD, USA). The sections were blindly presented for measurements by one examiner.

\section{Linear measurements}

The following linear measurements $(\mathrm{mm})$ were obtained in the mesial and distal roots under the furcation:

Defect extension $(D E)$ : linear extension of the total root surface between the two notches;

New cementum (NC): linear extension of the root surface covered by new cementum;

Connective Tissue Adaptation (CA): extension of the root surface covered by connective tissue without cementum.

New bone (NB): measured from a horizontal line connecting both notches (apical limit of the defect) to the most coronal extent of new bone.

\section{Area measurements}

A line connecting both notches defined the apical limit of the defect. The following parameters $\left(\mathrm{mm}^{2}\right)$ were obtained by the point counting technique:

Mineralized bone area (MBA): portion of the defect area filled with mineralized bone tissue;

Residual $B G$ particle area (RBG): portion of the defect area filled with $B G$ remaining particles;

Non-mineralized bone area (NMBA): portion of the defect area filled with non-mineralized tissue;

The measurements were performed using a microscope (Zeiss Axioskop 2, Carl Zeiss Instruments, Gottingen, Lower Saxony, Germany) with a 1.25/.035 objective associated with a video camera/computer/software (Image Pro Plus Version 3.0, Media Cybernetics).

\section{Statistical analysis}

Mean values for each parameter were obtained per defect. The mean values for all groups were 

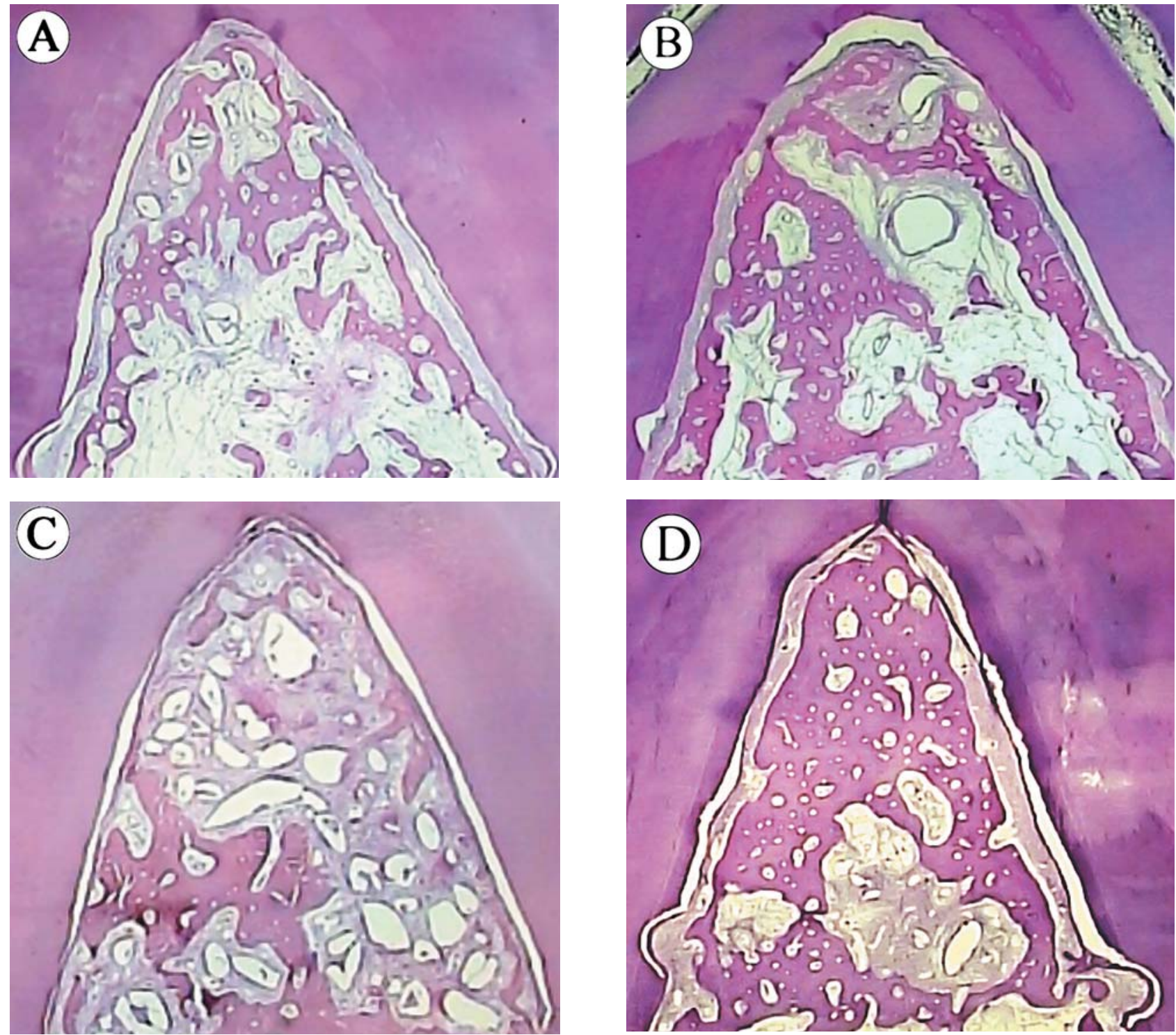

Figure 3- Mesiodistal histologic section of Class II furcation lesion stained with hematoxilyn and eosin (H\&E), (original magnification $x 20$ ); A) Site of the control group guided-tissue regeneration + bioactive glass (GTR+BG) after 45 days; B) Site of the test group guided-tissue regeneration + bioactive glass + platelet-rich plasma (GTR+BG+PRP) after 45 days; C) Site of the control group after 90 days; D) Site of the test group after 90 days. Both treatments promote defect filling in both periods however a greater mineralized bone area was observed for test group in both periods when compare with the control group

determined using the individual means from the 9 dogs. After testing the assumptions confirming normal distribution, two-way ANOVA was carried out to check any significance among the different treatment groups, any significance among the different time periods and the interaction between them. The $p$-value $\leq 0.05$ was considered statistically significant.

\section{RESULTS}

\section{Clinical observations}

Clinically, the healing response was favorable for all treatments. No suppuration or abscess formation was observed during the 90 days and no exposure of membranes was observed in both groups during the healing period. A clinical examination performed immediately before sacrifice, disclosed that the gingival margin of all sites was clinically normal and positioned coronal to the fornix of the buccal furcation.

\section{Histological observations}

There were no cases of epithelial downgrowth, ankylosis or extensive root resorption observed in all sites. No inflammation and foreign body reactions indicating toxicity were observed. A similar healing pattern was observed in the two groups, in both periods, regarding the filling of the defect (Figure 3). 
A continuous layer of new cementum had formed in the specimens of both groups extending coronally from the apical notches to a varying degree. However, in the group B, a more evident layer of new cementum was observed in the fornix region (coronal portion of the defect). In both groups, some small areas of the defects presented a very dense connective tissue surrounding the remaining BG particles. However, connective tissue adaptation with collagen fibers running parallel to the root surface seemed to be more frequent in group $A$.

Various defects in all groups presented bone surrounding BG particles and bone in direct contact with these graft particles (Figure 4). However, in
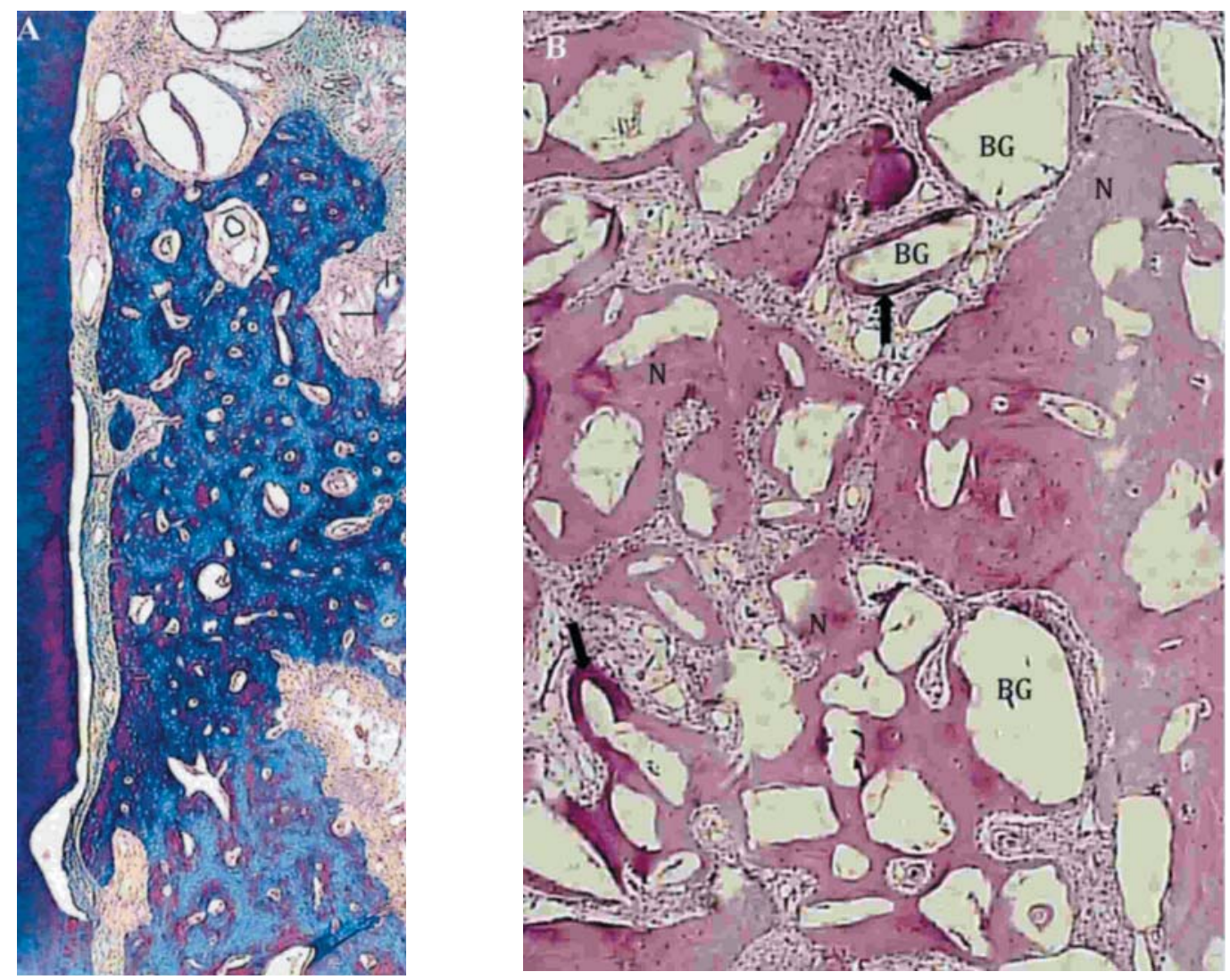

Figure 4- A) Photomicrograph of a mesiodistal histologic section of Class II furcation lesion platelet-rich plasma + bioactive glass + guided-tissue regeneration (PRP+BG+GTR) 90 days after treatment defect (Masson Trichrome staining, original magnification $\mathrm{x} 40$ ). New cementum (NC) was observed above the notch (N). Remaining BG particles were observed surrounded by new bone (NB), connective tissue (CT) and areas suggesting the presence of immature bone (IB) in contact with BG; B) Histologic section of the PRP+BG+GTR defect, 90 days after staining with hematoxilyn and eosin (H\&E), (original magnification $\times 100$ ). Remaining BG particles could be observed surrounded by NB and CT. Some areas indicated the new bone formation occurring around BG particles (arrows)

Table 1- Mean and Standard Deviation (SD) for the linear parameters evaluated after all the treatments (bioactive glass+guided-tissue regeneration and bioactive glass+platelet-rich plasma+guided-tissue regeneration) in both periods.

\begin{tabular}{ccccc}
\hline Mean \pm SD & Group A & (control group) & \multicolumn{2}{c}{ Group B (test group) } \\
Parameters & $\mathbf{4 5}$ days & $\mathbf{9 0}$ days & $\mathbf{4 5}$ days & $\mathbf{9 0}$ days \\
\hline New cementum $(\mathrm{mm})$ & $9.46 \pm 1.23^{\mathrm{Ba}}$ & $9.20 \pm 3.21^{\mathrm{Ba}}$ & $12.10 \pm 1.88^{\mathrm{Aa}}$ & $12.45 \pm 1.73^{\mathrm{Aa}}$ \\
Connective Tissue & $2.00 \pm 0.71^{\mathrm{Ba}}$ & $1.84 \pm 1.87^{\mathrm{Ba}}$ & $0.00 \pm 0.00^{\mathrm{Aa}}$ & $0.33 \pm 0.62^{\mathrm{Aa}}$ \\
Adaptation $(\mathrm{mm})$ & & & & \\
New bone $(\mathrm{mm})$ & $3.68 \pm 1.11^{\mathrm{Aa}}$ & $4.33 \pm 0.64^{\mathrm{Aa}}$ & $4.60 \pm 0.39^{\mathrm{Aa}}$ & $5.01 \pm 0.63^{\mathrm{Aa}}$ \\
Defect Extension & $11.88 \pm 1.17^{\mathrm{Aa}}$ & $11.14 \pm 2.80^{\mathrm{Aa}}$ & $12.10 \pm 1.88^{\mathrm{Aa}}$ & $12.78 \pm 1.41^{\mathrm{Aa}}$ \\
& & & & \\
\hline
\end{tabular}

Capital letters compare treatments within each time and non-capital letter compare times within each treatment. Means followed by different letters are statistically different 
Table 2-Mean and Standard Deviation (SD) for the area parameters evaluated after all the treatments (bioactive glass + guidedtissue regeneration and bioactive glass+platelet-rich plasma+guided-tissue regeneration) in both periods

\begin{tabular}{ccccc}
\hline $\begin{array}{c}\text { Mean } \pm \text { SD } \\
\text { Parameters }\end{array}$ & Group A & (control group) & \multicolumn{2}{c}{ Group B (test group) } \\
\hline $\begin{array}{c}\text { Mineralized Bone } \\
\text { Area }\left(\mathrm{mm}^{2}\right)\end{array}$ & $4.66 \pm 1.52^{\mathrm{Bb}}$ & $\mathbf{9 0}$ days & $\mathbf{4 5}$ days & $\mathbf{9 0}$ days \\
\hline $\begin{array}{c}\text { Non-mineralized bone } \\
\text { Area }\left(\mathrm{mm}^{2}\right)\end{array}$ & $7.16 \pm 2.49^{\mathrm{Aa}}$ & $4.10 \pm 0.63^{\mathrm{Ab}}$ & $4.34 \pm 0.48^{\mathrm{Ba}}$ & $2.58 \pm 0.69^{\mathrm{Bb}}$ \\
$\begin{array}{c}\text { Residual BG particles } \\
\text { Area }\left(\mathrm{mm}^{2}\right)\end{array}$ & $1.77 \pm 0.51^{\mathrm{Aa}}$ & $1.74 \pm 0.44^{\mathrm{Aa}}$ & $1.72 \pm 0.80^{\mathrm{Aa}}$ & $1.40 \pm 0.68^{\mathrm{Aa}}$ \\
\hline
\end{tabular}

Capital letters compare treatments within each time and non-capital letter compare times within each treatment. Means followed by different letters are statistically different

group $B$ the defects were filled by a higher density bone with a more evident mineralized bone area with islands of highly cellular bone marrow. In group $A$, the bone presented larger marrow spaces what could indicate a more immature bone when compared to group $B$.

\section{Histometric measurements}

The histometric results are shown in Tables 1 and 2. Data analysis showed a superior length of new cementum for group $B$ in both periods ( 45 days and 90 days $)(p<0.05)$. No statistically significant differences were observed between periods for the linear parameters for the two groups. The addition of PRP provided a greater mineralized bone area in both periods $(p<0.05)$. The non-mineralized bone area was greater in the control group $(p<0.05)$ in both periods while no statistically significant difference was observed in the area occupied by the remaining BG particles between groups. Significant differences between periods were observed in the mineralized bone area and non-mineralized bone area $(p<0.05)$.

\section{DISCUSSION}

The present study evaluated if the application of PRP on Class II furcation lesions would enhance periodontal regeneration when associated with GTR and bioactive glass (BG). Clinical reports have demonstrated that the association of GTR, bone substitutes and PRP could provide good results in the treatment of intrabony defects and class II furcation lesions, as revealed by gain in clinical attachment, defect fill at reentry, reducing probing depth, vertical defect fill and horizontal defect fill ${ }^{13,14}$. However, to the best of our knowledge, this is the first study that evaluated histologically the effect of the association of PRP with GTR and BG on periodontal regeneration of class II furcation lesions in dogs.

It has been demonstrated that when a bone graft or substitute is combined with the GTR procedure in furcation lesions, a greater amount of defect fill is observed ${ }^{3,14,15}$. This advantage can be explained by the osteoconductive and/or osteoinductive properties of the graft materials. One of the bone substitutes that have been investigated is the BG, a material that has been suggested as an osteoconductive graft $\mathrm{t}^{6,16,27}$. The use of $B G$ in the present study was not associated with any foreign body reaction. Healing events such as ankylosis and root resorption were not observed. This observation is in agreement with previous studies using BG in animals ${ }^{7,29}$. It was observed that some remaining BG granules showed dissolution of their core with the formation of new bone, as described by Vogel, et al. ${ }^{28}$ (2001).

The sites treated with GRT+BG (Group A) showed new cementum formation and new bone regeneration in both periods. These results are in accordance with previous reports, which demonstrated a beneficial effect of the association of GTR and bone substitutes ${ }^{14,15}$. However, clinical studies do not provide information about the nature of the healing process after these procedures.

In contrast with previous studies ${ }^{13,18,22}$, in the present investigation, there were no instances of epithelial downgrowth in all sites. In similar defects, Andrade, et al. ${ }^{1}$ (2007) observed a correlation between the exposure of the membrane and the epithelial migration. The presence of epithelial tissue was observed in all histological sections of the sites that shown a membrane exposure and was ascribed to the degradation of the exposed portions of this material.

The use of PRP for periodontal regeneration has been based on the idea that this preparation contains polypeptide growth factors (PGFs). Some specific PGFs, like PDGF and TGF $\beta$, could promote the growth and differentiation of the periodontal ligament and alveolar bone cells and could be responsible for the clinical improvement observed in experimental sites ${ }^{4,23}$. Other interesting feature 
of PRP is its sticky consistency due to its high fibrin content. The fibrin component of PRP may work as a hemostatic agent aiding in stabilizing the graft material and the blood clot $^{19}$. Blood clot immobilization has been suggested as an important event in the early phases of wound healing of periodontal regenerative procedures ${ }^{20,21}$.

It has been previously shown that PRP may stimulate PDL cells and fibroblastic cell proliferation ${ }^{10,11}$ but may suppress epithelial cell division in vitro ${ }^{17}$. Consequently, by ordering these cellular responses into a series of related events, PRP may facilitate wound-healing and tissue regeneration. In the present study, the sites in the Group B showed a superior cementum formation, in both observation periods, when compared with the sites of Group A $(p<0.05)$. To the best of our knowledge, no study provided direct evidence that the PRP could stimulate the differentiation of cells from the periodontal ligament to cementoblasts, inducing cementogenesis. However, previous investigations have suggested that the treatment with recombinant growth factors, such as PDGF and IGF may enhance the formation of cementum on denuded dentin surfaces ${ }^{4}$. In addition to it, a similar result was observed when the PRP was associated with a subepithelial connective tissue graft for the treatment of gingival recessions created in dogs $^{26}$.

The positive effect of PRP in the bone response was demonstrated by previous studies ${ }^{9,21}$ and could be evidenced in the present study by the largest area of mineralized bone observed in group B. Sites treated with PRP showed a superior mineralized bone area with a concomitant inferior non-mineralized bone area, in both periods, when compared with group $A(p<0.05)$. However, the difference between treatments is more evident in the first period (45 days) when the area of mineralized bone in group $B$ was almost twice the one observed in group A. This observation is in agreement with an in vitro study ${ }^{25}$ that suggested that PDGF acts upon osteoblastic cell proliferation, exerting most of its effects during the early phase of wound healing. Although the mineralized bone formation was superior in group $B$ of the present study, it should be noticed that recent animals studies could not demonstrate that PRP increases bone regeneration when used in peri-implant bone defects ${ }^{9}$.

To date, there is insufficient information about growth factor interactions and how they influence the activations of gene expression and protein production. Also, the ideal platelet and growth factor concentrations to promote periodontal regeneration has not been established. Lacoste, et al. ${ }^{12}$ (2003) reported that growth factors may act at specific times and at appropriate concentrations and this may be other explanation for the different results in studies with PRP. In the present study, the achieved percentage mean of platelet concentration was $227.02 \%$ (mean of 463,015 platelets $/ \mu \mathrm{L}$ ) in relation to blood platelet count.

The technique to produce PRP used in this study was previously described by Suaid, et al. ${ }^{26}$ (2008). This technique enables to produce a platelet concentration generally four times greater than the whole blood. Lacoste, et al. ${ }^{12}$ (2003) performed a study that measured the concentrations of bFGF, VEGF, PDGF-BB and TGF- $\beta 1$ released from platelet concentrate and whole blood, before and after the addition of calcium alone, thrombin alone and various concentrations of calcium and thrombin. They observed that calcium chloride, regardless of the use of thrombin, released platelet growth factors. In this study, the concentration of growth factors that was released was sufficient to promote endothelial cell proliferation in vitro ${ }^{12}$. Since the use of thrombin in this type of investigation is not allowed in our country, instead of thrombin, 10\% calcium chloride was added to PRP and heated in a water bath at $37^{\circ} \mathrm{C}$.

\section{CONCLUSIONS}

Within the limits of this animal study, it was concluded that PRP in association with GTR and BG may enhance the amount of new cementum and provide a more mineralized bone (mature) in a shorter period of time when applied to the treatment of class II furcation lesions in dogs. Future studies are required to clarify the mechanism of action of PRP in the periodontal regeneration process and the ideal platelet and growth factor concentrations to adequately promote periodontal regeneration.

\section{ACKNOWLEDGEMENTS}

The authors thank the financial support of FAPESP (The State of São Paulo Research Foundation, \#04/12428-6) and CNPq (National Counsel of Technological and Scientific Development \#300817/2007-0).

\section{REFERENCES}

1- Andrade PF, Souza SLS, Oliveira Macedo G, Novaes AB Jr, Moraes Grisi MF, Taba M Jr, et al. Acellular dermal matrix as a membrane for guided tissue regeneration in the treatment of Class II furcation lesions: a histometric and clinical study in dogs. J Periodontol. 2007;78:1288-99.

2- Evans GH, Yukna RA, Gardiner DL, Cambre KM. Frequency of furcation closure with regenerative periodontal therapy. J West Soc Periodontol Periodontal Abstr. 1996;44:101-9.

3- Fernandes JM, Rego RO, Spolidorio LC, Marcantonio RA, Marcantonio Júnior E, Cirelli JA. Enamel matrix proteins associated with GTR and bioactive glass in the treatment of class III furcation in dogs. Braz Oral Res. 2005;19:169-75. 
4- Giannobile WV, Hernandez RA, Finkelman RD, Ryan S, Kiritsy $C P$, D'Andrea $M$, et al. Comparative effects of platelet-derived growth factor-BB and insulin-like growth factor-I, individually and in combination, on periodontal regeneration in Macaca fascicularis. J Periodontal Res. 1996;31:301-12.

5- Gottlow J, Nyman S, Karring T, Lindhe J. New attachment formation as the result of controlled tissue regeneration. J Clin Periodontol. 1984;11:494-503.

6- Hall EE, Meffert RM, Hermann JS, Mellonig JT, Cochran DL. Comparison of bioactive glass to demineralized freeze-dried bone allograft in the treatment of intrabony defects around implants in the canine mandible. J Periodontol. 1999;70:526-35.

7- Hench LL, Paschall HA. Histochemical responses at a biomaterial's interface. J Biomed Mater Res. 1974;5:49-64.

8- Howell TH, Fiorellini JP, Paquette DW, Offenbacher S, Giannobile WV, Lynch SE. A phase I/II clinical trial to evaluate a combination of recombinant human platelet-derived growth factor-BB and recombinant human insulin-like growth factor-I in patients with periodontal disease. J Periodontol. 1997;68:1186-93.

9- Jensen TB, Rahbek O, Overgaard S, Søballe K. No effect of platelet-rich plasma with frozen or processed bone allograft around noncemented implants. Int Orthop. 2005;29:67-72.

10- Kawase T, Okuda K, Saito $Y$, Yoshie H. In vitro evidence that the biological effects of platelet-rich plasma on periodontal ligament cells is not mediated solely by constituent transforminggrowth factor-beta or platelet-derived growth factor. J Periodontol. 2005;76:760-7.

11- Kawase T, Okuda K, Wolff LF, Yoshie H. Platelet-rich plasmaderived fibrin clot formation stimulates collagen synthesis in periodontal ligament and osteoblastic cells in vitro. J Periodontol. 2003; 74:858-64.

12- Lacoste E, Martineau I, Gagnon G. Platelet concetrates: effects of calcium and thrombin on endothelial cell proliferation and growth factor release. J Periodontol. 2003;74:1498-1507.

13- Lekovic V, Camargo PM, Weinlaender M, Vasilic N, Aleksic Z, Kenney EB. Effectiveness of a combination of platelet-rich plasma, bovine porous bone mineral and guided tissue regeneration in the treatment of mandibular grade II molar furcations in humans. J Clin Periodontol. 2003;30:746-51.

14- Lekovic V, Camargo PM, Weinlaender M, Vasilic N, Kenney EB. Comparison of platelet-rich plasma, bovine porous bone mineral, and guided tissue regeneration versus platelet-rich plasma and bovine porous bone mineral in the treatment of intrabony defects: a reentry study. J Periodontol. 2002;73:198-205.

15- McClain PK, Schallhorn RG. Long-term assessment of combined osseous composite grafting, root conditioning, and guided tissue regeneration. Int J Periodontics Restorative Dent. 1993;13:9-27. 16- Nevins ML, Camelo M, Nevins M, King CJ, Oringer RJ, Schenk RK, et al. Human histologic evaluation of bioactive ceramic in the treatment of periodontal osseous defects. Int J Periodontics Restorative Dent. 2000;20:458-67.
17- Okuda K, Kawase T, Momose M, Murata M, Saito Y, Suzuki H, et al. Platelet-rich plasma contains high levels of platelet-derived growth factor and transforming growth factor-beta and modulates the proliferation of periodontally related cells in vitro. J Periodontol. 2003;74:849-57.

18- Payot P, Bickel M. Cimasoni G. Longitudinal quantitative radiodensitometric study of treated and untreated lower molar furcation involvements. J Clin Periodontol. 1987;14:8-18.

19- Polson AM, Garrett S, Stoller NH, Greenstein G, Polson AP, Harrold $C Q$, et al. Guided tissue regeneration in human furcation defects after using a biodegradable barrier: a multi-center feasibility study. J Periodontol. 1995;66:377-85.

20- Polson AM, Proye MP. Fibrin linkage: a precursor for new attachment. J Periodontol. 1983;54:141-7.

21- Ray AK, Jones AC, Carnes DL, Cochran DL, Mellonig JT, Oates TW Jr. Platelet-derived growth factor-BB stimulated cell migration mediated through p38 signal transduction pathway in periodontal cells. J Periodontol. 2003;74:1320-8.

22- Regazzini PF, Novaes AB Jr, Oliveira PT, Palioto DB, Taba M Jr, Souza $S L$, et al. Comparative study of enamel matrix derivative with or without GTR in the treatment of class II furcation lesions in dogs. Int J Periodontics Restorative Dent. 2004;24:476-87. 23- Sigurdsson TJ, Lee MB, Kubota K, Turek TJ, Wozney JM, Wikesjö UM. Periodontal repair in dogs: recombinant human bone morphogenetic protein-2 significantly enhances periodontal regeneration. J Periodontol. 1995;66:131-8.

24- Simonpietri-C JJ, Novaes AB Jr, Batista EL Jr, Feres Filho EJ. Guided tissue regeneration associated with bovine-derived anorganic bone in mandibular class II furcation defects. 6-month results at re-entry. J Periodontol. 2000;71:904-11.

25- Strayhorn CL, Garret JS, Dunn RL, Benedict JJ, Somerman MJ. Growth factors regulate expression of osteoblast-associated genes. J Periodontol. 1999;70:1345-54.

26- Suaid FF, Carvalho MD, Santamaria MP, Casati MZ, Nociti FH Jr, Sallum AW, et al. Platelet-rich plasma and connective tissue grafts in the treatment of gingival recessions: a histometrical study in dogs. J Periodontol. 2008;79:621-8.

27- Villaça JH, Novaes AB Jr, Souza SL, Taba M Jr, Molina GO, Carvalho TL. Bioactive glass efficacy in the periodontal healing of intrabony defects in monkeys. Braz Dent J. 2005;16:67-74. 28- Vogel M, Voigt C, Gross UM, Müller-Mai CM. In vivo comparison of bioactive glass particles in rabbits. Biomaterials. 2001;22:35762.

29- Wilson J, Clark AE, Hall M, Hench LL. Tissue response to bioglass endosseous ridge maintenance implants. J Oral Implantol. 1993; 19:295-302.

30- Yukna RA, Evans GH, Aichelmann-Reidy MB, Mayer ET. Clinical comparison of bioactive glass bone replacement graft material and expanded polytetrafluoroethylene barrier membrane in treating human mandibular molar class II furcations. J Periodontol. $2001 ; 72: 125-33$. 